\title{
EXAMINATION OF THE IMPACT OF DRYING TECHNIQUES IN SURFACE SIZING-COATING OPERATIONS ON THE QUALITY OF PAPER AND PRINTING
}

\author{
SEMIHA YENIDOGAN, ${ }^{*}$ CEM AYDEMIR, ${ }^{*}$ ARIF KARADEMIR ${ }^{* *}$ and \\ EMINE ARMAN KANDIRMAZ* \\ "Marmara University, School of Applied Sciences, Printing Technologies, Istanbul 34722, Turkey \\ ** Bursa Technical University, Faculty of Forestry, Department of Forest Industry Engineering, \\ Bursa 16310, Turkey \\ Corresponding author: Semiha Yenidogan, semihayavuz@marmara.edu.tr
}

Received October 23, 2018

\begin{abstract}
In order to improve the surface characteristics of paper, surface sizing and surface coating are applied to the surface of the paper. Filling the pores on the surface with polymerized substances and flatting the surface are aimed in both operations. Test papers are either left for air-drying or they could be heated in an oven to dry more quickly. Other drying techniques may also affect printing, as well as the optical and physical qualities of the paper.

In this study, starch-based sizing and calcium carbonated-starch-based coating operations were applied separately on paper surfaces. Some of the papers were allowed to dry at room temperature, and the others were dried in an oven. When the drying process was completed, paper gloss, water absorption and wettability qualities, as well as the CIE $\mathrm{L}^{*} \mathrm{a} \mathrm{b}^{*}$ color coordinates of all the papers were evaluated. In the following stage of the study, solid tone printing was applied on the surfaces of the papers - that had been subjected to different drying processes - using cyan colored ink in an IGT C1 printability tester. The effects of air-drying and oven-drying techniques in surface coating and sizing operations on the physical and printability characteristics of the paper were evaluated.
\end{abstract}

Keywords: surface modification, drying technique, printability, wettability

\section{INTRODUCTION}

There are two inputs in the printing industry: paper and ink. ${ }^{1}$ In order to produce high print quality, these two inputs need to have certain features. The surface characteristics of the paper are of great importance in the process of settling and absorption of liquid ink on the paper surface. Therefore, the surface structure of the paper is the most effective parameter for achieving print quality. $^{2}$

Paper porosity and absorbency towards various ingredients determine the ink holdout capacity, drying speed and print quality on the surface, which is described as print density. ${ }^{3,4}$ In order to achieve quality printing, it is desired for the ink to adhere to the surface of the paper, not to drag away from the pores to capillaries, and stay on the surface. Filling the pores among the paper fibers prevents the ink from dragging away.

Two techniques can be used to improve the surface structure and make it smoother: sizing of surface fibers and surface coating. Surface sizing is a manufacturing technique widely used in the paper industry to improve the physical properties of papers, to control liquid resistance and to enhance the printability of paper, including surface strength, wettability, surface morphology and barrier properties. ${ }^{5,6}$ In the sizing operations, the surface is covered with surface coating resins and the pores are closed. Thus, surface durability and liquid resistance would increase, and the printed ink is prevented from moving along within the paper. In the surface coating operation, the surface is smoothed out with the filling material that is added to the surface coating resin, the pores are filled, and the paper becomes more suitable for printing. ${ }^{7,8}$ Inorganic natural materials, such as calcium carbonate, are usually used as filling material due to their low cost. ${ }^{9,10}$ The coating operation aims to improve the optical and physical properties of paper, and provide 
better printability features. These features are usually surface smoothness, whiteness, opacity and paper gloss. ${ }^{11,12}$

In the surface sizing and surface coating operations, different types of starch are used as binder. Starch is a natural polymer composed of two important molecules: amylose and amylopectin. ${ }^{13,14}$ The wide availability of starch, its easy processing and low cost increase its potential areas of use. ${ }^{15}$

Using starch as binder in paper surface operations provides so many advantages to the paper, for example, developing resistance against liquid absorption (limiting absorption), increasing durability (tensile strength etc.), smoothing the surface out, and creating a scattering environment for solid components. ${ }^{16-20}$ Coating starches are modified by physical or chemical ways to enhance their existing positive features, to decrease their unwanted characteristics, or to bring new qualities. Ground starches, starches transformed by enzymes, starches oxidized with ammonium persulfate, starch ethers, and cationic starches are some starch types used in the paper industry. ${ }^{21-23}$ The most often used modified starch type in the paper industry is cationic starch, and with its use, waste is decreased by half. ${ }^{24,25}$

Both the sizing and coating operations that are applied to paper surfaces require a drying process before surface modification. There are two drying techniques that are commonly used. The first one is leaving paper surfaces to air-dry, and the other one is oven-drying, where papers are dried in a hot oven. The different drying speed of these techniques can affect the characteristics and printability of papers differently. For example, the polymerization of the binder with the oxygen on the surface of a paper that has been dried slowly may cause gloss problems; while in oven-dried papers, some yellowing may occur under the effect of the heat. Thus, with regard to printability, color printing applied to yellow papers or papers of other colors can yield different color results spectrophotometrically $(L * a * b *)$

One of the most important parameters affecting the quality of printing is how far the ink penetrates into the paper. The main reasons for the movement of the ink are the viscosity of the ink and the structure and quantity of the capillaries under the surface of the print materials (Fig. 1). Paper as a matrix for microfluidic inks offers many advantages compared to other materials, particularly due to its capability to transport liquid by capillary forces. ${ }^{26}$

Ink is made up of colorants (pigments and dyestuffs) that are dispersed or dissolved in a binding layer. Binding molecules in the structure of the ink (generally, resins and oils/solvents) move through the capillary pores of the paper. In every absorbent surface, capillaries can be used to indicate the movement of the ink. Some of the capillary pores are filled or closed with the surface sizing and coating. Thus, better results of coloring can be obtained on such paper surfaces because the binder and the colorant particles penetrate less into the paper.

Wettability is an important property of the substrate. $^{28}$ With regard to paper surfaces, it is very important in the choice of the printing ink, drying process, and the processes to be performed after printing (such as finishing, folding and binding). According to the wetting theory, solid surfaces with low surface energy values are able to resist against the spreading of liquids. ${ }^{29}$

The contact angle is measured at the solidliquid interface, as the angle from the tangent to the drop through the liquid to the solid surface. Contact angles from $0^{\circ}$ to $90^{\circ}$ degrees represent wetting, whereas angles from $90^{\circ}$ to $180^{\circ}$ degrees represent non-wetting. ${ }^{30}$

In this study, the effect of the air-drying and oven-drying step in the surface sizing and coating operations on the physical properties and printability of paper was investigated.

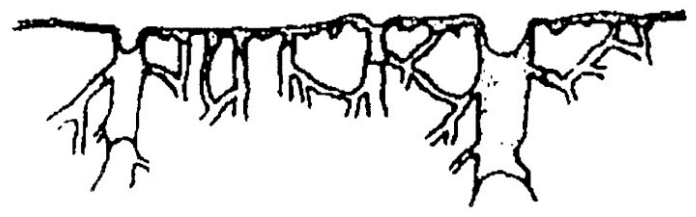

Figure 1: Capillary structure of paper ${ }^{27,20}$ 
Table 1

Properties of the wood-free paper substrate

\begin{tabular}{lccc}
\hline Properties & Unit & Standard & Wood-free uncoated paper \\
\hline Grammage & $\left(\mathrm{g} / \mathrm{m}^{2}\right)$ & ISO 536 & 200 \\
Thickness/caliper & $(\mu \mathrm{m})$ & TAPPI T 411 & 250 \\
Bulk (thickness/grammage) & $\left(\mathrm{cm}^{3} / \mathrm{g}\right)$ & ISO 534:1995 & 1.25 \\
Whiteness CIE D65/10 & $(\%)$ & ISO 11475 & 148 \\
Opacity with D65/10 & $(\%)$ & ISO 2471 & $>97$ \\
Gloss TAPPI 75 & $(\%)$ & TAPPI T480 om-92 & 3.8 \\
Surface roughness Bendtsen & $(\mu \mathrm{m} / \mathrm{Pas})$ & ISO 8791-2 & 300 \\
Surface energy & $\left(\mathrm{mJ} / \mathrm{m}^{2}\right)$ & ASTM D5946 & 39.3 \\
\hline
\end{tabular}

For this purpose, first, surface sizing and coating operations were conducted, and then airdrying and oven-drying were performed to papers in the laboratory. The physical properties and printability of all testing papers were assessed afterwards.

\section{EXPERIMENTAL}

Wood-free uncoated papers, with $200 \mathrm{~g} / \mathrm{m}^{2}$ density, were used for surface sizing and coating operations (Table 1). Cationic starch-based surface sizing was applied to standard paper surfaces. The mixture of cationic starch, with $7.5 \%$ concentration, was heated to $90{ }^{\circ} \mathrm{C}$ for this process. This hot sizing solution was cooled down to $60{ }^{\circ} \mathrm{C}$ afterwards, and it was applied to the paper surface, using the key bar in the paper coating device. Then, the same procedure was repeated for the coating operation, and $2.7 \%$ calcium carbonate was added to the sizing solution. Both the sized and the coated paper samples, as well as the untreated papers (control), were divided into two groups: one of them was allowed to air-dry for 24 hours at $23 \pm 1{ }^{\circ} \mathrm{C}$ and $50 \pm 2 \%$ relative humidity, and the other was placed in an oven to dry fully for 4 hours at $105 \pm 2{ }^{\circ} \mathrm{C}$.

The surface characteristics of the papers were then determined by contact angle measurements according to TAPPI T 458 standard. For the measurements, a Pocket Goniometer Model PG-X, (FIBRO Systems $\mathrm{AB}$, Sweden), program version 3.4., was used. A CCD video camera was used to display and record the contact angle of the water droplets (distilled water) to the paper surfaces. Surface free energy was calculated according to ASTM D5946 standard test method, depending on the water contact angle. ${ }^{31}$

The test papers were printed with process cyan ink (DIN ISO 2846-1) on an IGT C1 Offset printability tester, according to ISO $12647-2$ standard, at $300 \mathrm{~N} / \mathrm{m}$ constant pressure and equal ink density value. Then, to determine the printability values of these papers, print color changes, yellowing and print gloss measurements were performed.

The color and gloss of the papers were measured. Color CIE L*a*b* measurements were carried out on printed and unprinted, sized and coated paper surfaces according to ISO 12647-2:2013 standard, using an X-
Rite eXact ${ }^{\mathrm{TM}}$ spectrophotometer, in the spectral range from $400 \mathrm{~nm}$ to $700 \mathrm{~nm}$ (ISO 12647-1: D50 illuminant, $2^{\circ}$ observers, $0^{\circ} / 45^{\circ}$ geometry, black backing), using a polarized filter. Color differences $\left(\Delta E^{*}{ }_{a b}\right)$ on the samples were calculated according to the formula shown below (Eq. 1), according to CIE $\Delta E^{*} 1976$ ISO 13655 standard, by taking the average of ten measurements. ${ }^{27}$

$$
\Delta E_{a b}^{*}=\sqrt{\left(L_{2}^{*}-L_{1}^{*}\right)^{2}+\left(a_{2}^{*}-a_{1}^{*}\right)^{2}+\left(b_{2}^{*}-b_{1}^{*}\right)^{2}}
$$

where $\Delta L^{*}, \Delta a^{*}$ and $\Delta b^{*}$ are differences in $\mathrm{L}^{*}$, a* and $\mathrm{b}^{*}$ values between the color determined on the specimen and the target color.

Paper gloss measurements were performed with micro-gloss $75^{\circ}$ geometry, according to ISO 82541:2009 standard, print gloss measurements were carried out on a BYK-Gardner GmbH glossmeter, with micro-TRI-gloss $60^{\circ}$ geometry, according to ISO 2813:2014.

\section{RESULTS AND DISCUSSION Color changes of paper}

The perception of color changes varies from person to person, the degree of illumination of the place, and many other factors. $L^{*} a^{*} b^{*}$ is a system designed by CIE to eliminate these perception differences, by turning colors into mathematical expressions. In this system, $\mathrm{L}^{*}=$ lightness, $\mathrm{a}^{*}=$ + red/-green, $b^{*}=+$ yellow/-blue. The difference between two colors is expressed as $\Delta E^{*}{ }_{a b}$ on the color scale.

In this study, the CIE $L^{*} a^{*} b^{*}$ color values of untreated base papers (no sizing and coating) are as follows: $\mathrm{L}^{*}=93.83, \mathrm{a}^{*}=2.54, \mathrm{~b}^{*}=-7.57$. Color changes in the papers after air-drying and oven-drying, compared to the corresponding changes in the base paper, are given in Table 2. It may be noted from Table 2 that oven-drying changed the color (CIE $L^{*} a^{*} b^{*}$ ) of the untreated base papers more than air-drying, and it increased its yellowness $\left(b^{*}\right)$. On the untreated paper, airdrying caused a deviation that would not be normally perceived by the human eye, while oven-drying caused an effect that is visible to the 


\section{SEMIHA YENIDOGAN et al.}

trained eye. CIE $L^{*} a * b^{*}$ values of the sized and coated papers that were air-dried and oven-dried were determined, and the color changes were calculated according to $\Delta E$ formula, compared to those occurring on the untreated control paper. The results are tabulated in Table 3.

When every surface treatment is considered, oven-drying has changed the color of the papers more than air-drying. When $\Delta \mathrm{E}$ values of the papers are examined, it is found that air-drying caused an unnoticeable color change, while ovendrying caused a more pronounced effect, visible to the trained eye (Table 3). A possible explanation to this could be the fact that the double bonds in the natural starch polymer were partially broken because of the heat. This situation caused the starch to change its own specific color, and consequently, the paper lost gloss and color. Besides, oven-drying was noted to cause a higher color change in coated paper than in sized paper. This can be attributed to the presence of calcium carbonate in the coating formulation.

\section{Paper gloss}

In order to investigate the effect of different drying techniques on the gloss of papers treated by surface operations, gloss measurements were performed and the results are listed in Figure 2.

Surface sizing and surface coating operations have increased paper gloss, regardless of the drying technique. Comparing these two operations, surface sizing has increased paper gloss more than coating. It is thought that the reason surface coating increased gloss less than surface sizing is that calcium carbonate $\left(\mathrm{CaCO}_{3}\right)$ molecules absorb light and decrease the reflection. Thus, the sizing formulation on the surface of the paper increased gloss by reflecting light more strongly.

Table 2

Color changes on dried untreated paper

\begin{tabular}{lcccc}
\hline Applied process & $\Delta E^{*}{ }_{a b}$ & $\Delta L^{*}$ & $\Delta a^{*}$ & $\Delta b^{*}$ \\
\hline Air-drying & 0.28 & -0.2 & 0.02 & 0.26 \\
Oven-drying & 1.25 & -0.38 & 0.16 & 1.53 \\
\hline
\end{tabular}

Table 3

Color changes on sized and coated papers

\begin{tabular}{lcccc}
\hline Applied process & $\Delta E^{*}{ }_{a b}$ & $\Delta L^{*}$ & $\Delta a^{*}$ & $\Delta b^{*}$ \\
\hline Air-drying - Surface sizing & 0.58 & -0.44 & 0.31 & -0.4 \\
Oven-drying - Surface sizing & 1.05 & -0.12 & 0.67 & 1.04 \\
Air-drying - Surface coating & 0.55 & -0.49 & 0.19 & -0.28 \\
Oven-drying - Surface coating & 1.98 & -0.62 & 0.55 & 2.29 \\
\hline
\end{tabular}

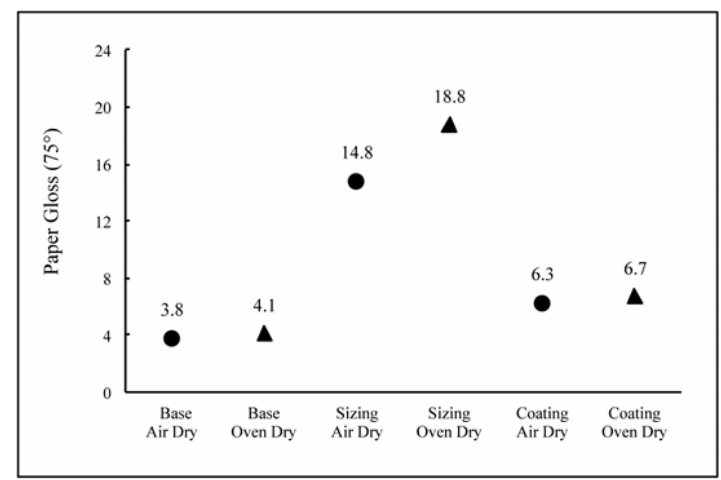

Figure 2: Effect of drying techniques on paper gloss 


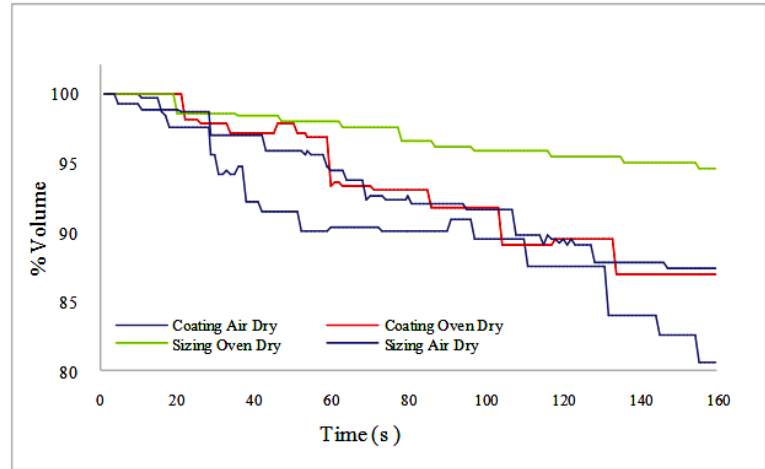

Figure 3: Water absorption on paper after surface treatment (sessile water drop test)

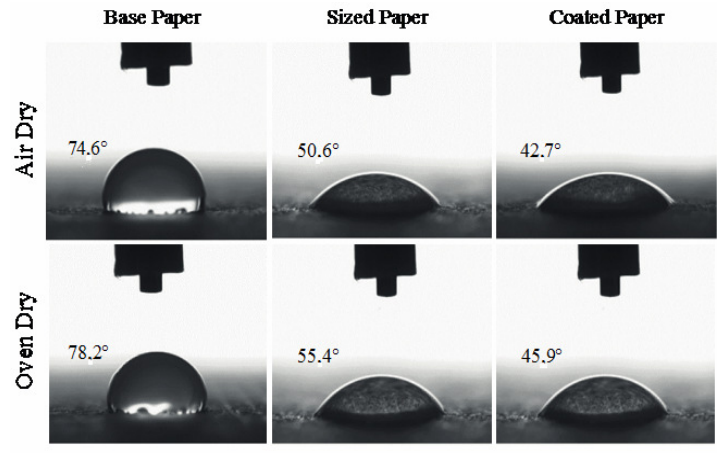

Figure 4: Contact angle and sessile water drop on paper surfaces (CCD camera)

On untreated papers, drying processes have not caused any particular changes in gloss. However, when the surface-treated papers are examined closely, it can be observed that ovendrying has increased paper gloss more than airdrying (Fig. 2). The reason behind this is that the high temperature used in oven-drying prevented the coating resin from penetrating deeper into the capillaries and was polymerized faster. Thus, the coating resin was less oxidized during the ovendrying process, resulting in brighter paper surfaces.

\section{Drop volume, contact angle and surface energy}

In this study, in order to determine the impact of different drying techniques on liquid absorbance and wettability of papers, drop volume change and contact angle measurements were performed by the sessile water drop technique on all the test papers as a function of time. Also, surface energies were calculated.

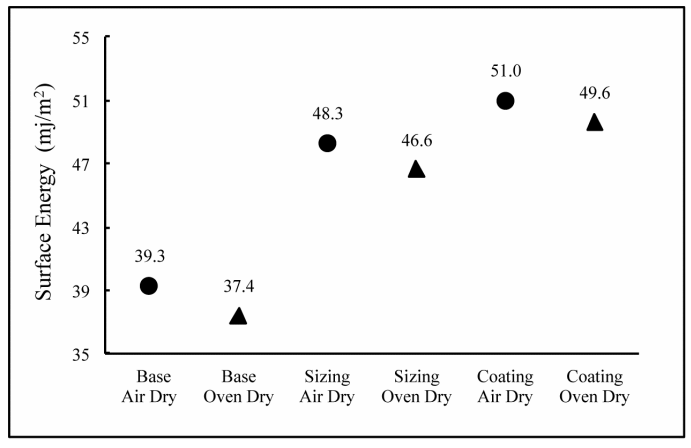

Figure 5: Effect of drying techniques on paper surface energies

Droplets of water were placed on the surfaces of the test papers, and the volume changes of the droplets were assessed over time. Thus, it was observed that the air-dried papers showed the fastest absorbance, while oven-dried papers presented the slowest absorbance (Fig. 3). This could be explained by the fact that, under the heat of the oven, the cell walls of cellulose were degraded, leading to the formation of an incrustation. This serves as an additional coating that decreases the water affinity of cellulose. To conclude, the oven-drying technique increased the liquid resistance of papers.

The images of the sessile water drops confirm that, on the sized and coated papers, the contact angles of the water droplets have decreased, while the surface energies of these papers have increased. The lowest contact angle and the greatest surface energy were obtained for the coated papers.

In comparison with the oven-drying technique, air-drying decreased the contact angle of the 
sessile water drop and increased the surface energy on all the paper surfaces (Figs. 4 and 5). Thus, it can be concluded that the air-drying technique increases the wettability of paper, while oven-drying decreases it. The possibility to cover a larger area of paper surface with a smaller amount of ink would arise, due to higher wettability and lower contact angle on the paper

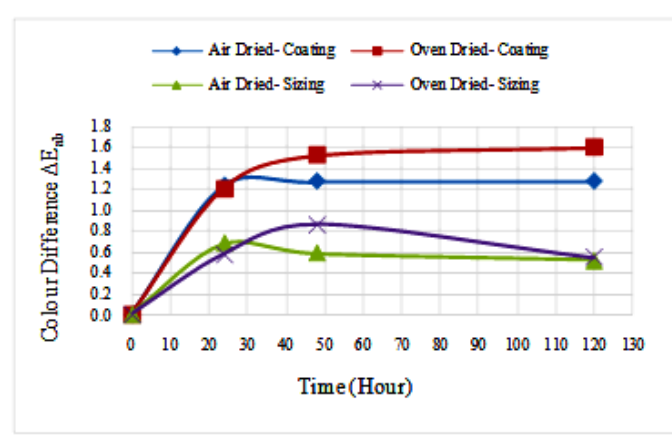

Figure 6: Effect of drying techniques on printing color change (cyan)

\section{Print color changes}

Process cyan color printing was applied to the papers treated by different surface operations, and color changes as a function of time were measured as CIE $\Delta \mathrm{E}^{*}$ (Eq. 1). As a result, it could be concluded that, in both sized and coated papers, printed colors changed over time more in oven-dried papers, compared to the air-dried ones (Fig. 6). The conclusion is that the oven-drying technique affects the color of the treated paper surface more in comparison with the air-drying technique. Under the effect of the heat in ovendrying, the double bonds in the cationic starch from the sizing and coating formulations broke, causing the printed color to change more significantly over time.

Also, a deeper change occurred on the coated surfaces, compared to the sized ones. This was attributed to the side reactions with calcium carbonate, which caused a color change in the paper support itself and thus affected the print color as well.

\section{Print gloss}

In the printability tests, it was determined that the ink film gloss on the sized papers was higher than that on the coated ones (Fig. 7). The reason for the high print gloss on the sized papers lies in the fact that the surface pores of the paper were surface. Also, a smaller amount of ink on the paper surface means that the ink film would dry in a shorter time, requiring smaller energy consumption. Due to quicker drying, printing problems, such as contamination, will occur less and finishing processes after printing, such as folding and binding, can be started in a shorter time.

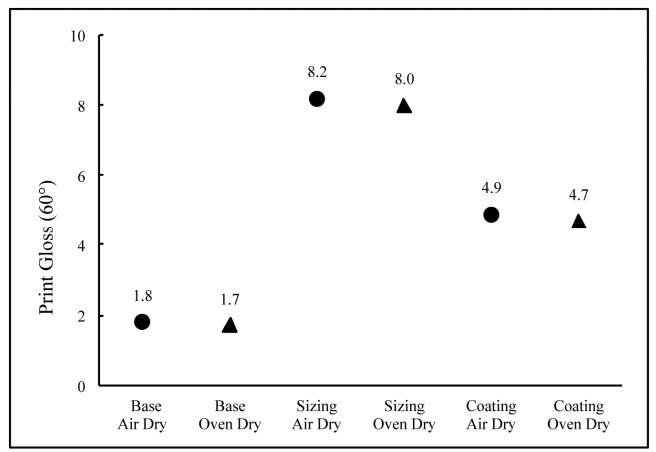

Figure 7: Effect of drying techniques on print gloss

covered with the resin from the sizing formulation, which increased liquid resistance in the paper. Thus, the printed ink was prevented from moving forward into the paper, and greater print gloss was obtained.

The lower print gloss on the coated papers may have two possible explanations. Firstly, the calcium carbonate particles used in the coating formulation dispersed the reflection, while increasing surface roughness. This limited both paper and print gloss. Secondly, the calcium carbonate absorbed the liquid on the surface, allowing it to penetrate deeper into its structure. In other words, the varnish providing ink gloss was wrapped with calcium carbonate, forming nodes. The liquid phase in the printed ink was absorbed by the coating material and less varnish remained on the surface to provide print gloss.

In the papers treated by both surface operations, the air-drying technique produced slightly higher print gloss (Fig. 7), demonstrating that oven-drying limits the print gloss. Moreover, the same situation was observed in the untreated papers, without any surface sizing or coating.

\section{CONCLUSION}

In the present study, paper was subjected to sizing and coating operations and then air-dried or oven-dried to investigate the effect of the drying 
techniques on the color, gloss and surface properties. It was concluded that the oven-drying technique affects the color of paper more significantly than air-drying, especially in coated papers, where oven-drying caused deeper print color changes. Air-drying enhanced print gloss, while oven-drying contributed to higher surface contact angle and lower surface energy in all the papers, thus leading to a decrease in surface wetting. Therefore, especially in applications requiring higher liquid resistance (such as in packaging), the sizing operation followed by oven-drying should be preferred. However, in applications where high ink density is used and quick ink absorption and drying are desired, airdrying is recommended for both sized and coated paper surfaces, as oven-drying in this case will slow down ink penetration.

\section{REFERENCES}

1 Y. Arai and K. Nojima, Tappi J., 81, 5 (1997).

2 C. Aydemir, Marmara Journal of Pure and Applied Sciences, 26, 3 (2014).

3 A. Karademir, S. Yenidoğan, C. Aydemir and H. Kucuk, Int. J. Polym. Mater., 61, 357 (2012), https://doi.org/10.1080/00914037.2011.584231

4 A. Karademir, C. Aydemir and S. Yenidoğan, Afr. J. Agric. Res., 6, 28 (2011), https://academicjournals.org/journal/AJAR/article-fulltext-pdf/B58BA4832195

5 M. Stankovsk, J. Gigac, M. Letko and E. Opalena, Wood Res., 59, 1 (2014).

6 C. Gang, Z. Penghui, K. Yudi, L. Yu and L. Donghan et al., Appl. Surf. Sci., 409, 45 (2017), https://doi.org/10.1016/j.apsusc.2017.02.201

H. K. Navaz, B. Markicevic, A. R. Zand, Y. Sikorski and E. Chan et al., J. Colloid Interface Sci., 325, 440

(2008),

https://doi.org/10.1016/j.jcis.2008.04.078

8 C. Aydemir, Int. J. Polym. Mater., 59, 6 (2010), https://doi.org/10.1080/00914030903538470

9 K. Stränger, in "Surface Application of Paper Chemicals", edited by J. Brander and I. Thorn, Springer, Netherlands, 1997, pp. 9-20.

${ }^{10}$ C. Aydemir, Z. Özomay, A. Karademir and E. A. Kandırmaz, Sci. Eng. Compos. Mater., 20, 141 (2013), DOI: https://doi.org/10.1515/secm-2012-0070

11 Y. Li, Q. Wang, W. Gu and B. He, in Procs. MEBE International Conference, China, March 28-30, 2015, pp. 817-820.

Y. Xiang, D. Desjumaux, D. Bousfield and M. F. Forbes, in Procs. CPPA, Quebec, Canada, 1998, pp. 85-91.

13 K. W. Kirby, in Procs. Tappi Conference, Atlanta, 1985, pp. 59.
14 A. Özcan and Ö. Zelzele, Mus Alparslan University Journal of Science, 5, 1 (2017).

15 R. L. Kearney, "Blade Coating Seminar", Tappi Press, Atlanta, 1988, pp. 99.

16 H. L. Lee, J. Y. Shin, C. H. Koh, H. Ryu, D. J. Lee et al., Tappi J., 1, 1 (2002).

17 C. P. Klass, "Development of Metered Size Press: A Historical Perspective", Metered Size Press Forum III, 1, Tappi Press, Atlanta, GA, 2000.

18 B. Bobek, U. Hamm and W. Dietz, "Process optimization to avoid calcium carbonate problems", Abschlußbericht InforProjekt 35, Department of Paper Technology and Mechanical Process Engineering, Technical University of Darmstadt, Germany, 2004.

19 S. Schabel, H. J. Putz, U. Hamm, A. Kersten, B. Bobek et al., Tappi J., 13, 11 (2014)

20 C. Aydemir and C. Özakhun, in "Matbaa Malzeme Bilimi”, Marmara Üniversitesi Yayınları, 2014, pp. 95.

21 D. S. Greif and J. C. Koval, "Starch and Starch Products in Paper Coating”, edited by R. L. Kearney and H. W. Maurer, Tappi Press, Atlanta, 1990, p. 29.

22 I. J. Bradshaw and J. F. Kennedy "Starch: Chemistry and Technology", edited by R. L. Whistler, J. N. BeMiller and E. F. Paschall, Academic Press, Orlando, Florida, 1984, pp. 26-86.

23 R. F. Sirois, Pap. Technol., 33, 11 (1992).

24 J. Mayatt, in Procs. The Chemistry of Papermaking, Pira International, UK, 1993.

25 D. Glittenberg and A. Becker, Рар. Рии., 79, 4 (1997).

26 F. Ciolacu, Cellulose Chem. Technol., 52, 863 (2018),

http://www.cellulosechemtechnol.ro/pdf/CCT910(2018)/p.863-871.pdf

27 C. Aydemir, S. Yenidoğan, A. Karademir and E. Arman, Mater. Manuf. Process., 32, 1310 (2017), https://doi.org/10.1080/10426914.2017.1279323

28 C. Aydemir, S. Yenidoğan, A. Karademir and E. A. Kandirmaz, J. Appl. Biomater. Funct., 16, 3 (2018), https://doi.org/10.1177/2280800018764761

29 S. Fukuda, N. M. Belgacem, D. Chaussy and N. R. C. Reverdy-Bruas, Cellulose Chem. Technol., 52, 5 (2018), http://www.cellulosechemtechnol.ro/pdf/CCT56(2018)/p.413-422.pdf

30 B. Thompson, in "Printing Materials, Science and Technology", Pira International, 2004, p. 178.

31 ASTM D5946-01 Standard Test Method for Corona-Treated Polymer Films using Water Contact Angle Measurements. 